\title{
Oral administration of D-aspartate, but not L-aspartate, depresses rectal temperature and alters plasma metabolites in chicks
}

\author{
Edi Erwan a , Vishwajit Sur Chowdhury ${ }^{\text {b }}$, Mao Nagasawa a , Ryosei Goda a , Tsuyoshi Otsuka a , \\ Shinobu Yasuo a ${ }^{a}$ Mitsuhiro Furuse ${ }^{\mathrm{a}, *}$ \\ a Laboratory of Regulation in Metabolism and Behavior, Graduate School of Bioresource and Bioenvironmental Sciences, Kyushu University, Fukuoka 812-8581, Japan \\ b Division for Arts and Science, Faculty of Arts and Science, Kyushu University, Fukuoka 819-0395, Japan
}

\section{A R T I C L E I N F O}

Article history:

Received 23 October 2013

Accepted 19 May 2014

Available online 29 May 2014

\section{Keywords:}

L-Aspartate

D-Aspartate

Body temperature

Plasma metabolites

Chicks

\begin{abstract}
A B S T R A C T
Aims: L-Aspartate (L-Asp) and D-aspartate (D-Asp) are physiologically important amino acids in mammals and birds. However, the functions of these amino acids have not yet been fully understood. In this study, we therefore examined the effects of L-Asp and D-Asp in terms of regulating body temperature, plasma metabolites and catecholamines in chicks.

Main methods: Chicks were first orally administered with different doses $(0,3.75,7.5$ and $15 \mathrm{mmol} / \mathrm{kg}$ body weight) of L- or D-Asp to monitor the effects of these amino acids on rectal temperature during 120 min of the experimental period.

Key findings: Oral administration of D-Asp, but not of L-Asp, linearly decreased the rectal temperature in chicks. Importantly, orally administered D-Asp led to a significant reduction in body temperature in chicks even under high ambient temperature (HT) conditions. However, centrally administered D-Asp did not significantly influence the body temperature in chicks. As for plasma metabolites and catecholamines, orally administered D-Asp led to decreased triacylglycerol and uric acid concentrations and increased glucose and chlorine concentrations but did not alter plasma catecholamines.

Significance: These results suggest that oral administration of D-Asp may play a potent role in reducing body temperature under both normal and HT conditions. The alteration of plasma metabolites further indicates that D-Asp may contribute to the regulation of metabolic activity in chicks.
\end{abstract}

(c) 2014 Elsevier Inc. All rights reserved.

\section{Introduction}

Amino acids can exist in two enantiomers-L-amino acids and Damino acids. Aspartate (Asp), one of the non-essential amino acids, plays various roles not only as a constituent of protein but also as a bioactive molecule. Asp occupies a unique position in intermediary metabolic activity, particularly in the mitochondria, where it plays important roles in nitrogen and energy metabolism (Stegink, 1976). L- and D-Asp have been shown to exist in various brain regions of chickens (Neidle and Dunlop, 1990) and pigeons (Kera et al., 1996). It has been reported that the injection of D-Asp released the antidiuretic hormone arginine vasopressin (AVP) in rats (Koyuncuoğlu et al., 1984). However, little is known about the function of D-Asp during early development when its level is physiologically high (Errico et al., 2008). In

\footnotetext{
* Corresponding author at: Laboratory of Regulation in Metabolism and Behavior, Faculty of Agriculture, Kyushu University, Fukuoka 812-8581, Japan. Tel.: + 8192642 2953; fax: +8192642 2954

E-mail address: furuse@brs.kyushu-u.ac.jp (M. Furuse).
}

mammals, it has been shown that oral administration of D-Asp, but not of L-Asp, decreased rectal temperature (Koyuncuoğlu et al., 1982a; Koyuncuoğlu and Berkman, 1982) and plasma triacylglycerol (TG) in rats (Koyuncuoğlu et al., 1982b). In addition, Monda et al. (2003) suggested the possibility of an association between Asp and interscapular brown adipose tissue that regulates thermogenesis in rats. Furthermore, we have demonstrated elsewhere that intracerebroventicular (i.c.v.) injection of either L-Asp or D-Asp clearly attenuates stress responses in chicks (Yamane et al., 2009; Erwan et al., 2012). Thus, L- or D-Asp may act as functional amino acids in chicks.

Various nutritional strategies have been used to overcome the adverse effects of heat stress in poultry (Austic, 1985; Leeson, 1986; Teeter and Belay, 1996; Yahav, 2000). These effects cause a reduction in egg size, in laying percentage, in egg shell durability, and in body weight gain, and increase mortality in layers (Sterling et al., 2003; Lin et al., 2004; Franco-Jimenez and Beck, 2007). Nutrients, especially amino acids, are widely used as anti-stress agents with regard to psychological and physiological stress (Yamane et al., 2009; Hamasu et al., 2010; Erwan et al., 2012). Amino acid supplementation, in particular that involving essential amino acids, has been performed in an 
attempt to overcome heat-stress problems in birds (Mendes et al., 1997; Rose and Salah Uddin, 1997; Daghir et al., 2003).

To our knowledge, there have been no reports regarding the effect of L- or D-Asp on thermogulation in chicks. Therefore, the first purpose of this study was to examine the effect of orally administered L- and D-Asp on rectal temperature and plasma metabolites in chicks. The second purpose was to investigate the effect of orally administered D-Asp on the regulation of body temperature and plasma catecholamines under high ambient temperature (HT) conditions. Since the effects of the catecholamines on body temperature differ among species (Andersson et al., 1966; Findlay and Robertshaw, 1967; Cooper et al., 1965; Marley and Stephenson, 1975; Takahashi et al., 2005), we examined the norepinephrine (NE) and epinephrine (E) concentrations in chicks under HT. The third aim was to analyze the central effect of D-Asp on thermoregulation. Thus, i.c.v. administration of D-Asp was carried out to investigate its effect on rectal temperature in chicks.

\section{Materials and methods}

\section{Animals and drugs}

One-day-old male layer chicks (Julia) (Gallus gallus domesticus) were purchased from a local hatchery (Murata hatchery, Fukuoka, Japan) and housed in a wire-meshed cage $(50 \times 35 \times 33 \mathrm{~cm})$ in a group (20-25 birds) at a constant temperature of $30 \pm 1{ }^{\circ} \mathrm{C}$ and with continuous light. Chicks were all of the same age and were housed without any adult present. Food (AX, Toyohashi Feed and Mills Co. Ltd., Aichi, Japan) and water were provided ad libitum. One day before the experiment, chicks ( 4 days old) were reared individually and assigned for treatment and control groups on the basis of their body weight in order to produce uniform groups. This study was performed in accordance with the guidelines for animal experiments carried out in the Faculty of Agriculture and on the Graduate Course of Kyushu University, and adhered to Law no. 105 and Notification no. 6 of the government.

L- and D-Asp were purchased from Wako Pure Chemical Industries (Osaka, Japan).

\section{Administration of L- or D-Asp}

Following an acclimatization period with individual rearing, chicks were randomly selected and divided into four groups in Experiments 1 and 2, each group consisting of 8 chicks. The birds were provided with ad libitum access to the diet during the whole experimental period. On the day of the experiment, each chick (5 days old) was orally administered either a solution of L-Asp (Experiment 1) or D-Asp (Experiment 2 ) for the treatment groups, or distilled water (DW) for the control group, via an elastic plastic needle on a small syringe. Finkelstein et al. (1983) determined the plasma L-Asp concentration at 0, 15, 30, 45, 60 , and $120 \mathrm{~min}$ after applying different doses of L-Asp $(0,1.88,3.76$, $4.89,5.64$ and $7.52 \mathrm{mmol} / \mathrm{kg}$ body weight). The plasma L-Asp concentration was minimally influenced by less than $3.76 \mathrm{mmol} / \mathrm{kg}$ body weight (Finkelstein et al., 1983). Thus, in the present study, for oral administration of L-Asp or D-Asp in Experiments 1 and 2, we used 3.75, 7.5 and $15.0 \mathrm{mmol} / \mathrm{kg}$ body weight as the low, medium and high levels, respectively.

In Experiments 3 and 4, following the habituation period with individual rearing, the birds (at 6 days old) were randomly selected and divided into groups. All the birds were provided with ad libitum access to the diet during the whole experimental period. In Experiment 3, two groups of chicks were orally injected with DW and then exposed to either $\mathrm{HT}\left(35^{\circ} \mathrm{C} ; 120 \mathrm{~min}\right)(n=6)$ or the control thermoneutral temperature (CT, $\left.30^{\circ} \mathrm{C} ; 120 \mathrm{~min}\right)(n=8)$. A third group of chicks $(n=8)$ was orally administered with D-Asp ( $15 \mathrm{mmol} / 10 \mathrm{ml} / \mathrm{kg}$ body weight) and then exposed to $\mathrm{HT}\left(35^{\circ} \mathrm{C} ; 120 \mathrm{~min}\right)$. In Experiment 4, the D-Asp was administered by i.c.v. injection via a microsyringe into the left lateral ventricle of the chicks, according to the method of Davis et al. (1979).
The dose of D-Asp for i.c.v. was based on the findings of our previous report (Erwan et al., 2012). In brief, chicks were i.c.v. injected either with D-Asp $(1.68 \mu \mathrm{mol} / 10 \mu \mathrm{l})$ as the treatment or with the same volume of saline as the control. All the experiments were done during the day time (09:00-17:00). Two groups of chicks were i.c.v. injected with saline and then exposed to either HT $\left(35^{\circ} \mathrm{C} ; 180 \mathrm{~min}\right)(n=7)$ in a chamber (Sanyo Electric Co. Ltd., Japan; catalog number: Sanyo MIR-253) or $\mathrm{CT}\left(30^{\circ} \mathrm{C} ; 180 \mathrm{~min}\right)(n=8)$ by being placed in their cages on similar racks. A third group of chicks $(n=8)$ was i.c.v. administered with D-Asp and then exposed to HT ( $\left.35^{\circ} \mathrm{C} ; 180 \mathrm{~min}\right)$.

At the end of the experiments, birds were decapitated following anesthesia with isoflurane (Mylan Inc., Japan). Blood samples were collected in heparinized tubes and centrifuged at $10,000 \times \mathrm{g}$ at $4{ }^{\circ} \mathrm{C}$ for 4 min. Plasma was stored at $-80{ }^{\circ} \mathrm{C}$ until assay. TG, glucose (Glu), total cholesterol (TCHO), total protein (TP), uric acid (UA), calcium (Ca), aspartate aminotransferase (AAT), magnesium (Mg), sodium $(\mathrm{Na})$, potassium $(\mathrm{K})$, chlorine $(\mathrm{Cl})$ and amylase (Amyl) in the plasma were measured in Experiments 1 and 2. Plasma NE and E levels were investigated in Experiment 3.

\section{Measurement of rectal temperature}

The rectal temperature of chicks was measured with a digital thermometer with an accuracy of $\pm 0.1{ }^{\circ} \mathrm{C}$ (Thermalert TH-5, Physitemp Instruments Inc., USA) by inserting the thermistor probe into the cloaca to a depth of 1-2 cm. Rectal temperature was measured at 30-, 60- and 120-min after oral injection and at 30-, 120- and 180-min after i.c.v. injection.

\section{Analysis of plasma metabolites}

The plasma metabolites, including TG, Glu, TCHO, TP, UA, Ca, AAT, $\mathrm{Mg}, \mathrm{Na}, \mathrm{K}, \mathrm{Cl}$ and Amyl, were measured with Fuji Drychem-7000 (Fuji Medical System, Co. Ltd., Tokyo, Japan).

\section{Analysis of plasma NE and $E$}

Plasma NE and E were analyzed by means of the alumina absorption method (as described by Takahashi et al., 2005). Briefly, plasma was diluted with Tris buffer ( $\mathrm{pH} 7.8$ ) and $30 \mathrm{mg}$ of alumina was added to absorb NE and E from the plasma. After removal of the liquid phase, the alumina was rinsed with ultrapure water and transferred to centrifuge-filtration units (Ultra Free C3-GV, Millipore, Bedford, MA, USA). Alumina-absorbed NE and E were separated by adding $2 \%$ acetic acid solution, and then the solution was filtrated at $4{ }^{\circ} \mathrm{C}, 2000 \times \mathrm{g}$, for $4 \mathrm{~min}$. The $30 \mu \mathrm{l}$ filtrate was injected into an HPLC system (Eicom, Kyoto, Japan) with an ODS column (SC-5ODS, Eicom, Kyoto, Japan) for measurement of NE and $\mathrm{E}$. The mobile phase consisted of $1 \mathrm{M}$ phosphoric acid buffer ( $\mathrm{pH}$ 6.0), $3 \mathrm{mM}$ sodium octanesulfonate, and $134 \mu \mathrm{M}$ EDTA. NE and E were detected using an electrochemical detector (ECD-300, Eicom, Kyoto, Japan) at an applied potential of $450 \mathrm{mV}$. Dihydroxybenzlamine was used to confirm the accuracy of the NE and E extraction. The external standard was used to identify peaks eluting in the chromatogram according to retention time and conformation. The system's detection limit for NE and $\mathrm{E}$ was $0.1 \mathrm{pg} / \mathrm{sample.}$

\section{Statistical analysis}

For the rectal temperature, a repeated-measures two-way analysis of variance (ANOVA) was applied for Experiments 1-4. In Experiments 1 and 2, plasma metabolites were statistically analyzed by one-way ANOVA and regression equations. Plasma NE and E were statistically analyzed by one-way ANOVA, and the Tukey test was done as a post hoc test. Significant differences were denoted as $P<0.05$. Values were presented as means \pm S.E.M. Statistical analysis was carried out using the commercially available package SAS (Version 9.1, SAS Institute, Cary, 
U.S.A., 2002). All data in each group were first subjected to a Thompson rejection test as described by Kobayashi and Pillai (2013) to eliminate outliers $(P<0.01)$, and the remaining data were used for the analysis among groups.

\section{Results}

Experiment 1. Effects of the orally administered L-Asp on rectal temperature and plasma metabolites

As shown in Fig. 1, rectal temperatures of chicks did not change significantly following oral administration of L-Asp $\left(\mathrm{F}_{(3,24)}=0.31\right.$, $P>0.05)$. Table 1 shows the effect of oral administration of several doses of L-Asp on the concentration of plasma metabolites. There was no significant effect of L-Asp on the concentration of plasma metabolites except for increasing the TCHO concentration $\left(\mathrm{F}_{(3,26)}=3.15, P<0.05\right)$. However, no correlation was found between TCHO and levels of L-Asp.

Experiment 2. Effects of the orally administered D-Asp on rectal temperature and plasma metabolites

Changes in the rectal temperatures following the oral administration of the different doses of D-Asp are shown in Fig. 2. D-Asp significantly $\left(F_{(3,18)}=4.00, P<0.05\right)$ decreased rectal temperature and also showed a significant effect of time $\left(F_{(2,6)}=41.39, P<0.0001\right)$ and an interaction between dose and time $\left(\mathrm{F}_{(6,36)}=5.05, P<0.001\right)$, implying that the effect of the treatment was to consistently reduce the rectal temperature as the experimental time progressed. Table 2 shows the changes in plasma metabolites following the oral administration of D-Asp. A significant $(P<0.05)$ negative correlation was detected between the administered doses of D-Asp and the plasma concentration of TG (55.4 [SE 6.0] - 1.6 [SE 0.7] X, $\left.R^{2}=0.161\right)$. Plasma TG concentration showed a significant decrease, by $7.5 \mathrm{mmol} / \mathrm{kg}$ body weight D-Asp, compared with the control $\left(F_{(3,27)}=3.78, P<0.05\right)$. In addition, a significant $(P<0.05)$ negative correlation was found between the administered doses of D-Asp and the plasma concentration of UA (9.50 [SE 0.6] - 0.14 [S E0.1] X, $\left.R^{2}=0.131\right)$. On the other hand, a significant $(P<0.05)$ positive correlation was observed between the administered doses of D-Asp and the plasma concentration of Glu (248 [SE 4.7] + 1.4 [SE 0.5] X, $R^{2}=$ $0.204)$. Furthermore, a significant $(P<0.001)$ positive correlation was detected between the administered doses of D-Asp and the plasma concentration of $\mathrm{Cl}\left(98.4\right.$ [SE 1.1] +0.5 [SE 0.13] X, $\left.R^{2}=0.341\right)$. The values

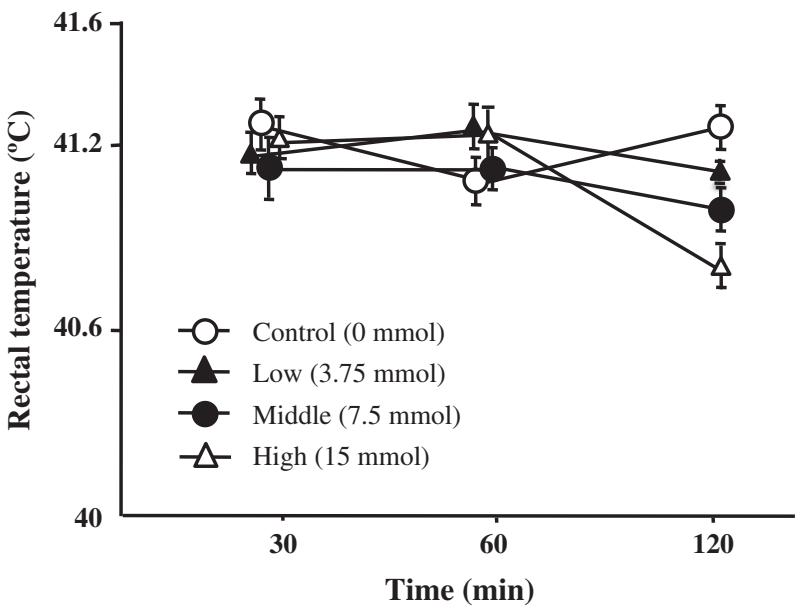

Fig. 1. Effect of L-Asp administration on rectal temperatures in chicks during $120 \mathrm{~min}$ of the experimental period. The number of chicks used in each group ranged between 5 and 8 . Values are means \pm S.E.M. of TP, TCHO, Amyl, Ca, AAT, Mg, Na and K showed no significant changes in any of the treated groups.

Experiment 3. Effects of the orally administered D-Asp on rectal temperature and plasma catecholamines in HT-exposed chicks

Fig. 3 shows the changes in rectal temperature in response to D-Asp under HT in comparison with the changes in rectal temperature in response to DW under CT and HT (control birds). D-Asp significantly reduced rectal temperature $\left(\mathrm{F}_{(2,19)}=11.64, P<0.001\right)$ and also showed a significant effect of time $\left(F_{(2,4)}=7.75, P<0.005\right)$ and an interaction between treatment and time $\left(\mathrm{F}_{(4,38)}=3.97, P<0.01\right)$, suggesting that the effect of D-Asp on declining body temperature became increasingly prominent as the treatment time progressed. In control birds, exposure to HT significantly increased rectal temperature at 30 and $60 \mathrm{~min}$ $(P<0.05)$. The rectal temperature of chicks administered with D-Asp and exposed to HT was lowered at 60 and 120 min compared with the control birds exposed to HT $(P<0.01)$. The rectal temperature of birds administered with D-Asp under HT at 120 min was even lower than that of the control birds under CT $(P<0.01)$. This denotes that the suppressive effect on rectal temperature of a single oral dose of D-Asp was lasting within the experimental time; the interaction between D-Asp and time was characterized by a reduction in rectal temperature, while the opposite was the case for the control groups.

Fig. 4 shows the plasma concentrations of $\mathrm{NE}$ and $\mathrm{E}$ at the end of the total treatment period of $120 \mathrm{~min}$. NE concentrations did not differ according to whether the treatment was HT or D-Asp $\left(F_{(2,18)}=0.97\right.$, $P>0.05)$. D-Asp administration tended to increase plasma E concentration, but this effect was not significant $\left(\mathrm{F}_{(2,18)}=2.07, P>0.05\right)$.

Experiment 4. Effects of the i.c.v. administration of D-Asp on rectal temperature in HT-exposed chicks

The i.c.v. injection of D-Asp had no effect $\left(\mathrm{F}_{(2,15)}=1.18, P>0.05\right)$ on body temperature, while body temperature significantly $\left(F_{(2,4)}=\right.$ 20.96, $P<0.0001$ ) increased as time progressed (Fig. 5). No significant interactions between the treatment and time $\left(F_{(4,30)}=0.44, P>0.05\right)$ were observed.

\section{Discussion}

A variety of data derived from studies involving rats have shown that L-Asp is a neurotransmitter in the central nervous system. L-Asp is not only concentrated in nerve endings (Gundersen et al., 1991), but is also found localized and accumulated in common synaptic vesicles (Gundersen et al., 1998; Fleck et al., 2001). However, the role of L-Asp has been questioned as the information was limited in avian species (Bungo et al., 2002). Thus, this study was focused on examining the effects of L-Asp and its enantiomer D-Asp on the regulation of rectal temperature and plasma metabolites in chicks. Furthermore, the concentrations of the plasma catecholamines were analyzed to clarify their physiological relevance to D-Asp and thermoregulation in birds. In the current study, L-Asp was not found to influence rectal temperature. The results of the current experiments confirmed previous findings which showed that oral administration of L-Asp did not decrease rectal temperature in rats (Koyuncuoğlu et al., 1982a; Koyuncuoğlu and Berkman, 1982). However, we recently found that when L-Asp was chemically conjugated with lauric acid, a medium-chain fatty acid (Lauroyl-L-Asp), it had the potential to decrease body temperature (Erwan et al., 2013a). Thus, the chemical modification of L-Asp assists in its development of new functions.

Investigation of plasma metabolites in birds and mammals enables metabolic alterations to be determined that are due to the effects of several factors, including physiological state, pharmacological condition, age, husbandry condition, and genetic type (Meluzzi et al., 1991; Harr, 2002; Gayathri et al., 2004; Juráni et al., 2004; Alonso-Alvarez, 2005; Yanni et al., 2005, 2010). In the present study, we therefore examined 
Table 1

Effects of oral administration of several doses of L-Asp on plasma metabolites in chicks.

\begin{tabular}{|c|c|c|c|c|}
\hline \multicolumn{5}{|l|}{ L-Asp (mmol) } \\
\hline Items & 0 & 3.75 & 7.5 & 15 \\
\hline Glucose $(\mathrm{mg} / \mathrm{d} l)$ & $248 \pm 4$ & $252 \pm 5$ & $245 \pm 4$ & $254 \pm 4$ \\
\hline Total cholesterol (mg/dl) & $159 \pm 5^{\mathrm{ab}}$ & $145 \pm 4^{\mathrm{b}}$ & $170 \pm 8^{\mathrm{a}}$ & $151 \pm 7^{\mathrm{ab}}$ \\
\hline Amylase (IU) & $1,346 \pm 93$ & $1,233 \pm 147$ & $1,279 \pm 82$ & $1,306 \pm 227$ \\
\hline Total protein (g/dl) & $2.82 \pm 0.05$ & $2.74 \pm 0.07$ & $3.09 \pm 0.12$ & $2.89 \pm 0.12$ \\
\hline Calcium $(\mathrm{mg} / \mathrm{dl})$ & $12.6 \pm 0.1$ & $12.7 \pm 0.1$ & $12.9 \pm 0.3$ & $12.6 \pm 0.1$ \\
\hline Aspartate aminotransferase (IU) & $151 \pm 4$ & $156 \pm 5$ & $155 \pm 7$ & $136 \pm 3$ \\
\hline Triacylglycerol (mg/dl) & $78 \pm 9$ & $52 \pm 7$ & $72 \pm 9$ & $48 \pm 8$ \\
\hline Uric acid $(\mathrm{mg} / \mathrm{dl})$ & $10.0 \pm 0.6$ & $10.0 \pm 0.5$ & $10.7 \pm 1.0$ & $10.2 \pm 0.3$ \\
\hline Magnesium (mg/dl) & $2.30 \pm 0.06$ & $2.29 \pm 0.07$ & $2.23 \pm 0.05$ & $2.18 \pm 0.04$ \\
\hline Sodium $(\mathrm{mEq} / \mathrm{l})$ & $140 \pm 0$ & $140 \pm 1$ & $140 \pm 0$ & $141 \pm 1$ \\
\hline Potassium (mEq/l) & $5.4 \pm 0.1$ & $5.4 \pm 0.1$ & $5.5 \pm 0.3$ & $5.4 \pm 0.3$ \\
\hline Chlorine $(\mathrm{mEq} / \mathrm{l})$ & $100 \pm 1$ & $101 \pm 1$ & $99 \pm 1$ & $103 \pm 2$ \\
\hline
\end{tabular}

Means with different superscripts were significantly different at $P<0.05$.

Values are means \pm SEM. The number of samples used for analysis was 5-8.

the concentrations of TG, TCHO, TP, UA, Ca, AAT, Amyl, Mg, Na, K and Cl to estimate whether the physiological condition of chicks was changed as a result of the oral administration of L- or D-Asp. In the current experiment, when L-Asp was administered, no significant changes were observed in plasma Glu, Amyl, TP, Ca, AAT, TG, UA, Mg, Na, K or Cl. Tada et al. (2008) found that subchronic oral administration of L-Asp with a dietary concentration of up to $5.0 \%$ had no influence on serum Glu, Na, $\mathrm{K}$, or $\mathrm{Cl}$ in rats. In the present experiment the findings of no significant changes in AAT or UA were similar to the previous findings of Schieber et al. (1997), who demonstrated that there was no change in serum AAT or UA in chicks following supplementation of L-Asp during the 28 days of the experimental period. Furthermore, Delaney et al. (2008) and Karaman et al. (2011) also confirmed that oral administration of L-Asp or N-acetyl-L-aspartic acid, an N-acetylated derivative of L-Asp, had no influence on TG, Glu, TP, Na, $\mathrm{K}$ or $\mathrm{Cl}$. The results of the present study and previous studies indicate that short-term or even long-term administration of L-Asp or its derivative may not alter the plasma metabolites in chicks and rats.

The effects of L-Asp on lipid metabolism remain unclear. It has been demonstrated that orally administered L-Asp and L-glutamate inhibited fatty streak initiation in cholesterol-fed rabbits (Yanni et al., 2003). Yanni et al. (2003) indicated that when rabbits were fed with a diet of cholesterol plus corn oil or supplemented with Asp and glutamate for 4 weeks, serum levels of TCHO, TG, low-density lipoprotein cholesterol and apolipoprotein B were not altered, but they found that these two

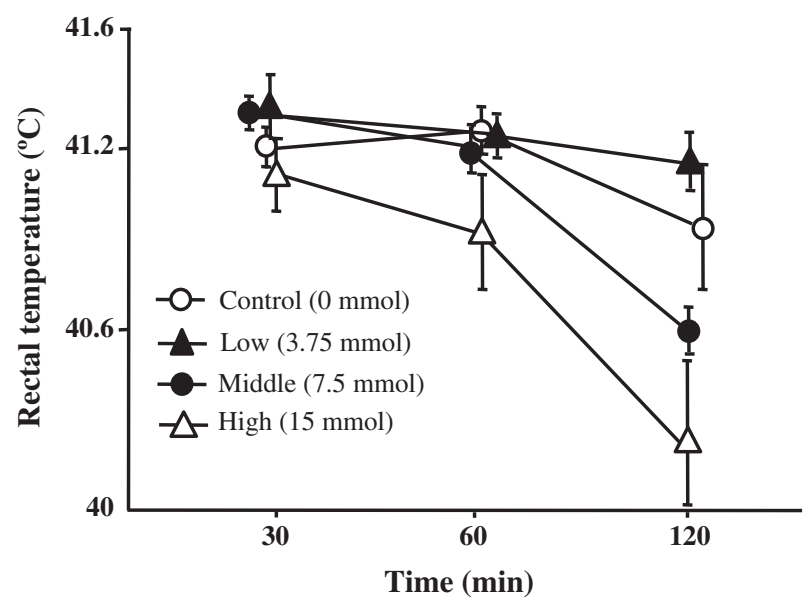

Fig. 2. Effect of D-Asp administration on rectal temperatures in chicks during 120 min of the experimental period. The number of chicks used in each group ranged between 5 and 6. Values are means \pm S.E.M. amino acids increased high-density lipoprotein cholesterol. However, the underlying mechanisms were not elucidated. The present findings contrasted with previous findings in rats where L-Asp, given for 90 days, caused a significant decrease in plasma TCHO concentration (Tada et al., 2008). These discrepancies in the TCHO concentration in response to L-Asp may be due to variations in experimental period, differences in doses, or species differences. Further experimentation would be needed to clarify the factors involved in this disparity.

In Experiment 2, it was clearly observed that orally administered DAsp decreased rectal temperature. D-Asp has previously been found to be an agent causing body temperature to decrease in rats (Koyuncuoğlu et al., 1982a; Koyuncuoğlu and Berkman, 1982). Although in the present study we were not able to determine the weight of feces or the volume of urine, it has been suggested elsewhere that the administration of D-Asp decreases rectal temperature and consequently decreases fecal weight as well as volume of urine (Koyuncuoğlu et al., 1982b). In addition, Koyuncuoğlu et al. (1982b) revealed that food intake and rectal temperature significantly decreased when rats received D-Asp or D-Asp plus L-Asp in a 1:1 ratio. Since the analgesia is produced by $\mathrm{D}$-amino acids which are naloxone reversible, the decrease in rectal temperature may be caused by D-Asp (Koyuncuoğlu et al., 1982a). We reported that central administration of both $\mathrm{L}$ - and D-Asp induced sedative effects under an acutely stressful condition in chicks (Erwan et al., 2012). Recently, we have further found that central injection of L-Asp can induce sedative and hypnotic effects to attenuate stress behavior through the $N$-methyl- $D$-aspartate (NMDA) receptor, but the attenuation of stress behavior by D-Asp might be via the simultaneous involvement in this process of other receptors besides the NMDA receptor (Erwan et al., 2014). However, the question of whether the oral administration of D-Asp may work on other glutamatergic receptors in the central nervous system that are responsible for sedation in chicks has not yet been studied. Further research is needed to answer this question. Furthermore, several factors may contribute to the changes in rectal temperature induced by D-Asp. For example, nitric oxide causes vasodilatation in chicks (Hamal et al., 2010), and ghrelin induces the inhibition of food intake as well as decreasing the respiratory quotient in chicks (Saito et al., 2002; Geelissen et al., 2006). However, the question of whether D-Asp could modulate these factors has not yet been clarified. Additional experiments are needed to determine the relationships between D-Asp and other factors.

In the current study, plasma TG and UA were found to significantly decrease with the administration of D-Asp in comparison with the control chicks. This finding is consistent with the previous report by Kanjanapruthipong and Thaboot (2006), where it was revealed that decreased rectal temperature was associated with decreasing levels of $\beta$-hydroxybutyrate and serum UA in cows. It was further reported that D-Asp decreased food intake and TG in rats under free or restricted 
Table 2

Effects of oral administration of several doses of D-Asp on plasma metabolites in chicks.

\begin{tabular}{|c|c|c|c|c|}
\hline \multicolumn{5}{|l|}{ D-Asp (mmol) } \\
\hline Items & 0 & 3.75 & 7.5 & 15 \\
\hline Glucose (mg/dl) & $253 \pm 6^{\mathrm{ab}}$ & $251 \pm 6^{\mathrm{b}}$ & $249 \pm 2^{b}$ & $274 \pm 7^{\mathrm{a}}$ \\
\hline Total cholesterol (mg/dl) & $166 \pm 7$ & $161 \pm 9$ & $156 \pm 7$ & $161 \pm 5$ \\
\hline Amylase (IU) & $900 \pm 90$ & $1,045 \pm 144$ & $880 \pm 74$ & $905 \pm 81$ \\
\hline Total protein (g/dl) & $2.90 \pm 0.09^{\mathrm{a}}$ & $2.76 \pm 0.09^{\mathrm{ab}}$ & $2.59 \pm 0.06^{\mathrm{b}}$ & $2.85 \pm 0.06^{\mathrm{ab}}$ \\
\hline Calcium $(\mathrm{mg} / \mathrm{dl})$ & $12.8 \pm 0.2$ & $12.2 \pm 0.2$ & $12.4 \pm 0.2$ & $12.6 \pm 0.3$ \\
\hline Aspartate aminotransferase (IU) & $168 \pm 7$ & $153 \pm 6$ & $160 \pm 4$ & $162 \pm 8$ \\
\hline Triacylglycerol (mg/dl) & $65 \pm 13^{\mathrm{a}}$ & $42 \pm 5^{\mathrm{ab}}$ & $34 \pm 3^{b}$ & $37 \pm 4^{\mathrm{ab}}$ \\
\hline Uric acid $(\mathrm{mg} / \mathrm{dl})$ & $9.8 \pm 1.0$ & $9.4 \pm 0.5$ & $7.3 \pm 0.5$ & $8.0 \pm 0.7$ \\
\hline Magnesium (mg/dl) & $2.41 \pm 0.08$ & $2.30 \pm 0.09$ & $2.29 \pm 0.06$ & $2.36 \pm 0.05$ \\
\hline Sodium (mEq/l) & $137 \pm 2^{\mathrm{ab}}$ & $134 \pm 2^{\mathrm{b}}$ & $137 \pm 1^{\mathrm{ab}}$ & $141 \pm 1^{\mathrm{a}}$ \\
\hline Potassium (mEq/l) & $5.6 \pm 0.3$ & $5.4 \pm 0.2$ & $5.3 \pm 0.2$ & $5.7 \pm 0.3$ \\
\hline Chlorine $(\mathrm{mEq} / \mathrm{l})$ & $98 \pm 2^{\mathrm{b}}$ & $100 \pm 2^{\mathrm{ab}}$ & $102 \pm 1^{\mathrm{ab}}$ & $106 \pm 1^{\mathrm{a}}$ \\
\hline
\end{tabular}

Means with different superscripts were significantly different at $P<0.05$.

Values are means \pm SEM. The number of samples used for analysis was 6-8.

feeding conditions (Koyuncuoğlu et al., 1982b). Our previous study showed that oral administration of D-Asp decreased food intake (Erwan et al., 2013b), and the current results demonstrated that plasma TG concentration decreased in chicks as a result of administration of D-Asp. In another previous study we showed that i.c.v. administration of L-Asp, a precursor to D-Asp, increased plasma corticosterone concentration in chicks (Yamane et al., 2009). In addition, Marley and Stephenson (1975) revealed that hypothermia was associated with increased blood Glu concentration in chicks. Our planned future study will clarify the hormonal relationships and D-Asp-induced changes in plasma metabolites.

In Experiment 3, we confirmed a further constant reduction in rectal temperature following orally administered D-Asp in HT-exposed chicks. This finding raised the possibility that D-Asp may be a useful agent for reducing body temperature during summer heat stress. It is well documented that the global surface temperature is increasing (IPCC, 2013), and HT is a serious concern for birds in general as they have more difficulty than mammals in maintaining homeothermic body temperature (Ensminger et al., 1990; Chowdhury et al., 2012, 2014). Thus, our current findings might encourage others to think about the development of a drug to mitigate HT-related problems. In terms of plasma catecholamines (NE and $\mathrm{E}$ ), no significant changes were observed, which is a similar finding to that of our previous report where we showed that the i.c.v. or oral administration of L- or D-Asp did not alter brain catecholamine levels in chicks (Erwan et al., 2012, 2013b). Furthermore, Andersson et al. (1966) and Findlay and Robertshaw (1967) reported

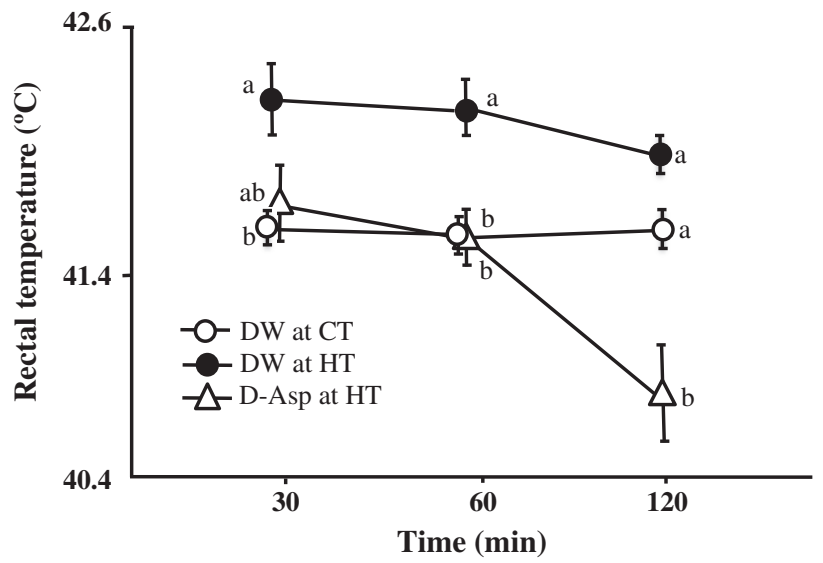

Fig. 3. Effect of oral administration of D-Asp on rectal temperatures under high ambient temperature (HT) in chicks during $120 \mathrm{~min}$ of the experimental period. The number of chicks used in each group ranged between 6 and 8 . Values are means \pm S.E.M. CT, control thermoneutral temperature. that the injection of $\mathrm{NE}$ and $\mathrm{E}$ did not alter rectal temperature in the goat (Capra hircus) or the ox (Bos taurus), respectively. Contrary to these findings, Cooper et al. (1965) and Bligh (1966) revealed that i.c.v. administration of NE caused an increase in rectal temperature in rabbits and sheep. It has also been reported that central injection of NE lowered the body temperature at 75 min after injection in 2-3-
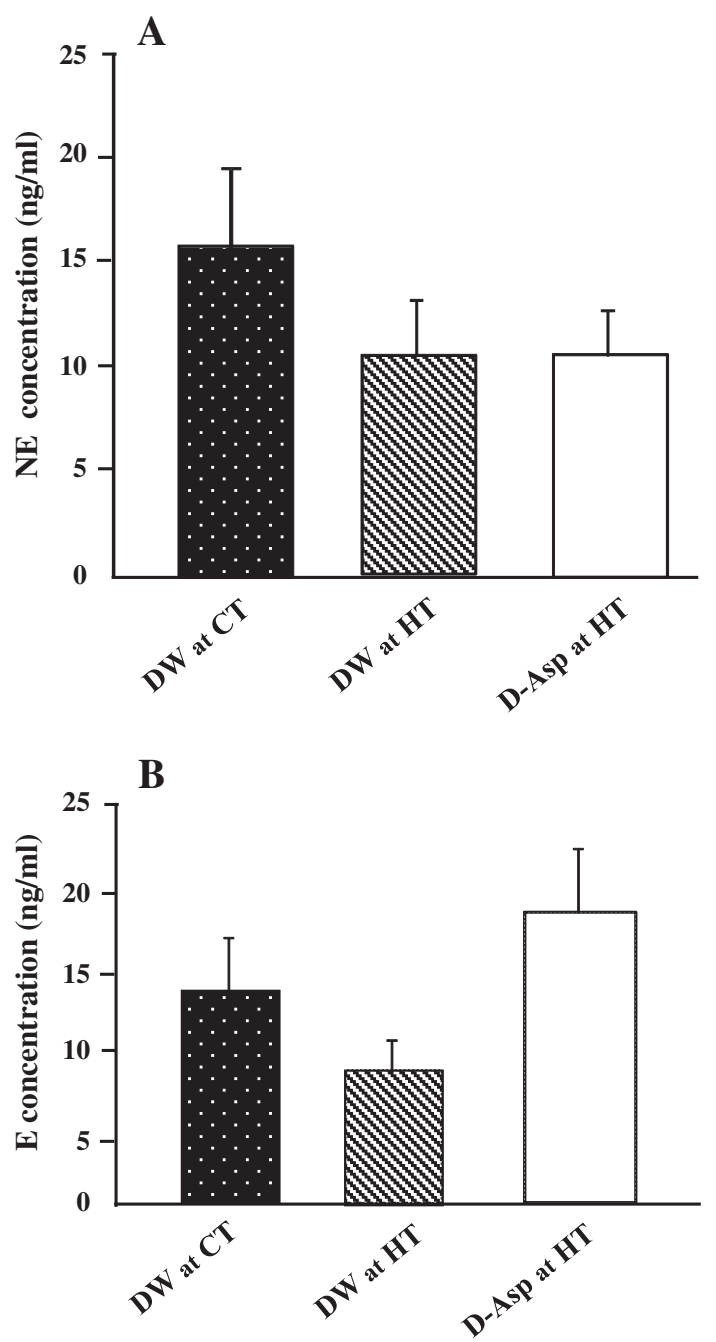

Fig. 4. Effect of oral administration of D-Asp on plasma norephinephrine (A) and epinephrine (B). The number of chicks used in each group ranged between 6 and 8 . Values are means \pm S.E.M. HT, high ambient temperature; $C$, control thermoneutral temperature. 


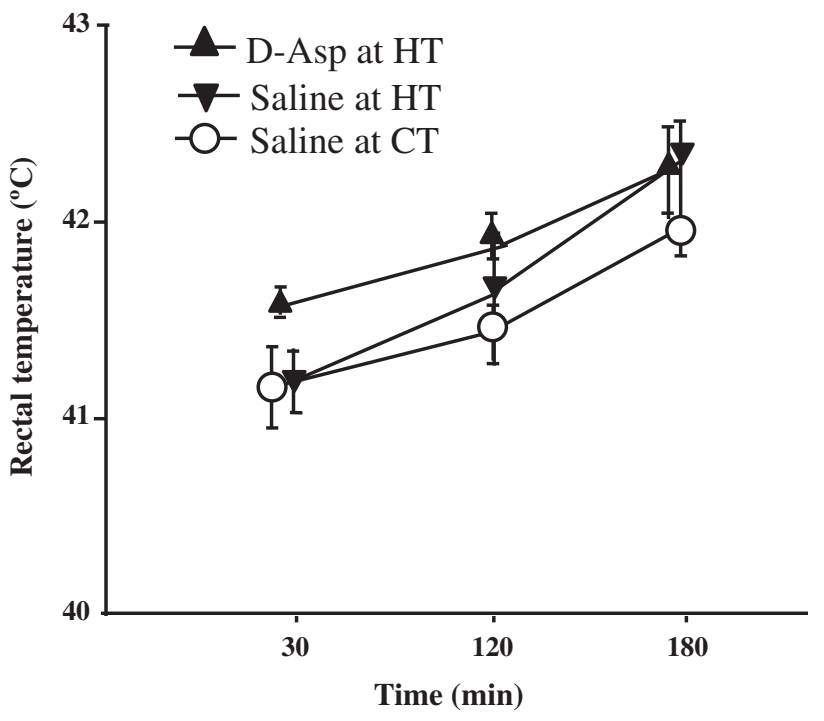

Fig. 5. Effect of intracerebroventricular (i.c.v.) injection of D-Asp on rectal temperatures under high ambient temperature (HT) and control thermoneutral temperature (CT) in chicks during 180 min of the experimental period. The number of chicks used in each group ranged between 5 and 6 . Values are means \pm S.E.M.

week-old chicks at a thermoneutral temperature and that body temperature returned to initial levels within 3-4 h (Marley and Stephenson, 1975). In the case of young chicks, Takahashi et al. (2005) demonstrated that i.c.v. injection of $\mathrm{E}$ did not significantly influence body temperature. Taken together, these results show that the body-temperaturelowering effect of D-Asp may not be related to that of E.

In Experiment 4, we demonstrated that i.c.v. injection of D-Asp definitely did not lead to a reduction in body temperature under HT, unlike the effect of oral injection of D-Asp under HT (Fig. 5). Previous reports revealed that the injection of $\mathrm{D}$-Asp released arginine vasopressin (AVP) in rats (Koyuncuoğlu et al., 1984; Okuno et al., 1965). In birds, the AVP homologous nonapeptide is arginine vasotocin (AVT) (Acher et al., 1970; Sawyer et al., 1961). AVT, a neurohypophyseal hormone in non-mammalian vertebrates, is involved in water balance in birds, acting in a way that is similar to the function of AVP in mammals (Stallone and Braun, 1986). Tachibana et al. (2004) demonstrated that i.c.v. injection of AVT increased the rectal temperature in chicks. However, central injection of D-Asp did not influence the body temperature in the present study. Thus, we can speculate at least that central D-Asp would not be able to stimulate the release of AVT in young chicks. On the other hand, body temperature showed an increasing tendency to rise following i.c.v. injection, as shown in Fig. 5; this may be due to the minimal amount of stress that is induced by i.c.v. injection. However, we have previously confirmed that feeding behavior (Furuse et al., 1999) and plasma corticosterone concentration (Koutoku et al., 2005) were not affected by the same process of i.c.v. injection.

\section{Conclusion}

Orally administered D-Asp, but not orally administered L-Asp, was found to cause the suppression of body temperature in neonatal chicks, along with the alteration of some plasma metabolites-namely, TG, UA, Glu and $\mathrm{Cl}$. Interestingly, orally administered D-Asp strongly suppressed body temperature in HT-exposed chicks. These results suggest that DAsp could be a useful amino acid for mitigating heat-stress problems in the poultry industry if it is provided through water/feed. A future study will focus on elucidating the mechanisms of the central and peripheral actions of D-Asp in thermoregulation.

\section{Conflict of interest statement}

The authors of this manuscript have nothing to declare.

\section{Acknowledgments}

This work was supported by a Grant-in-Aid for Scientific Research (No. 23248046 to MF) from the Japan Society for the Promotion of Science. EE would like to thank the Directorate General of Higher Education (DGHE) of Indonesia for supporting a scholarship for this study.

\section{References}

Acher R, Chauvet J, Chauvet MT. Phylogeny of the neurohypophysialhormones. The avian active peptides. Eur J Biochem 1970;17:509-13.

Alonso-Alvarez C. Age-dependent changes in plasma biochemistry of yellow-legged gulls (Larus cachinnans). Comp Biochem Physiol A Mol Integr Physiol 2005;140:512-8.

Andersson B, Jobin M, Olsson K. Serotonine and temperature control. Acta Physiol Scand 1966;67:50-6.

Austic RE. Feeding poultry in hot and cold climates. In: Yousef MK, editor. Stress Physiology in Livestock: Poultry. Florida, United States: CRC Press; 1985. p. 123-36.

Bligh J. Effects on temperature of monoamines injected into the lateral ventricles of sheep. J Physiol 1966;185:46P-7P.

Bungo T, Yoshinaga S, Ueda H. Intracerebroventricularly administered excitatory amino acids: effects on feeding behavior in chicks. J Appl Anim Res 2002;22:161-8.

Chowdhury VS, Tomonaga S, Nishimura S, Tabata S, Cockrem JF, Tsutsui K, et al. Hypothalamic gonadotropin-inhibitory hormone precursor mRNA is increased during depressed food intake in heat-exposed chicks. Comp Biochem Physiol A Mol Integr Physiol 2012;162:227-33.

Chowdhury VS, Tomonaga S, Ikegami T, Erwan E, Ito K, Cockrem JF, et al. Oxidative damage and brain concentrations of free amino acid in chicks exposed to high ambient temperature. Comp Biochem Physiol A Mol Integr Physiol 2014;169:70-6.

Cooper KE, Cranston WI, Honour AJ. Effects of intraventricular and intrahypothalamic injection of noradrenaline and 5-HT on body temperature in conscious rabbits. J Physiol 1965;181:852-64.

Daghir NJ, Farran MT, Barbour GW, Beck MM. Nutritive value of high-oil corn grown under semi-arid conditions and its impact on broiler performance and carcass composition. Poult Sci 2003;82:267-71.

Davis JL, Masuoka DT, Gerbrandt LK, Cherkin A. Autoradiographic distribution of L-proline in chicks after intracerebral injection. Physiol Behav 1979;22:693-5.

Delaney B, Amanda Shen Z, Powley CR, Gannon S, Munley SA, Maxwell C, et al. Acute and repeated dose oral toxicity of $\mathrm{N}$-acetyl-L-aspartic acid in Sprague-Dawley rats. Food Chem Toxicol 2008;46:2023-34.

Ensminger ME, Oldfield JE, Heinemann WW. Feeds and Nutrition. Clovis, CA: The Ensminger Publishing Company; 1990.

Errico F, Nisticò R, Palma G, Federici M, Affuso A, Brilli E, et al. Increased levels of daspartate in the hippocampus enhance LTP but do not facilitate cognitive flexibility. Mol Cell Neurosci 2008;37:236-46.

Erwan E, Tomonaga S, Yoshida J, Nagasawa M, Ogino Y, Denbow DM, et al. Central administration of L- and D-aspartate attenuates stress behaviors by social isolation and CRF in neonatal chicks. Amino Acids 2012;43:1969-76.

Erwan E, Chowdhury VS, Ito K, Furuse M. Lauroyl-L-aspartate decreased food intake and body temperature in neonatal chicks. Pharmacol Biochem Behav 2013a;113:7-11.

Erwan E, Tomonaga S, Ohmori T, Mutaguchi Y, Ohshima T, Nagasawa M, et al. Oral administration of D-aspartate, but not of L-aspartate, reduces food intake in chicks. J Poult Sci 2013b;50:164-71.

Erwan E, Chowdhury VS, Nagasawa M, Goda R, Otsuka T, Yasuo S, et al. Central injection of L- and D-aspartate attenuates isolation-induced stress behavior in chicks possibly through different mechanisms. Eur J Pharmacol 2014;736:138-42.

Findlay JD, Robertshaw D. The mechanism of body temperature changes induced by intraventricular injections of adrenaline, noradrenaline and 5-hydroxytryptamine in the ox (Bos taurus). J Physiol 1967;189:329-36.

Finkelstein MW, Daabees TT, Stegink LD, Applebaum AE. Correlation of aspartate dose, plasma dicarboxylic amino acid concentration, and neuronal necrosis in infant mice. Toxicology 1983;29:109-19.

Fleck MW, Barrionuevo G, Palmer AM. Synaptosomal and vesicular accumulation of Lglutamate, L-aspartate and D-aspartate. Neurochem Int 2001;39:217-25.

Franco-Jimenez DJ, Beck MM. Physiological changes to transient exposure to heat stress observed in laying hens. Poult Sci 2007;86:538-44.

Furuse M, Ando R, Bungo T, Ao R, Shimojo M, Masuda Y. Intracerebroventricular injection of orexins does not stimulate food intake in neonatal chicks. Br Poult Sci 1999;40: 698-700.

Gayathri KL, Shenoy KB, Hegde SN. Blood profile of pigeons (Columba livia) during growth and breeding. Comp Biochem Physiol A Mol Integr Physiol 2004;138:187-92.

Geelissen SM, Swennen Q, Geyten SV, Kühn ER, Kaiya H, Kangawa K, et al. Peripheral ghrelin reduces food intake and respiratory quotient in chicken. Domest Anim Endocrinol 2006;30:108-16.

Gundersen V, Ottersen OP, Storm-Mathisen J. Aspartate- and glutamate-like immunoreactivities in rat hippocampal slices: depolarization-induced redistribution and effects of precursors. Eur J Neurosci 1991;3:1281-99.

Gundersen V, Chaudhry FA, Bjaalie JG, Fonnum F, Ottersen OP, Storm-Mathisen J. Synaptic vesicular localization and exocytosis of L-aspartate in excitatory nerve terminals: 
a quantitative immunogold analysis in rat hippocampus. J Neurosci 1998;18: 6059-70.

Hamal KR, Wideman RF, Anthony NB, Erf GF. Differential expression of vasoactive mediators in microparticle-challenged lungs of chickens that differ in susceptibility to pulmonary arterial hypertension. Am J Physiol Regul Integr Comp Physiol 2010;298: R235-42.

Hamasu K, Shigemi K, Tsuneyoshi Y, Yamane H, Sato H, Denbow DM, et al. Intracerebroventricular injection of L-proline and D-proline induces sedative and hypnotic effects by different mechanisms under an acute stressful condition in chicks. Amino Acids 2010;38:57-64

Harr KE. Clinical chemistry of companion avian species: a review. Vet Clin Pathol 2002 $31: 140-51$.

Intergovernmental Panel on Climate Change (IPCC). Climate Change 2013: The Physical Science Basis. Contribution of Working Group I to the Fifth Assessment Report of the Intergovernmental Panel on Climate Change; 2013. [http://www.climatechange2013. org/images/uploads/WcGIAR5_WGI-12Doc2b_FinalDraft_All.pdf].

Juráni M, Výboh P, Zeman M, Lamošová D, Košt'ál L, Blažíiček P. Post-hatching dynamics of plasma biochemistry in free-living European starlings (Sturnusvulgaris). Comp Biochem Physiol A Mol Integr Physiol 2004;138:89-95.

Kanjanapruthipong J, Thaboot B. Effects of neutral detergent fiber from rice straw on blood metabolites and productivity of dairy cows in the tropics. Asian Aust J Anim Sci 2006;3:356-62.

Karaman S, Barnett Jr J, Sykes GP, Delaney B. Subchronic oral toxicity assessment of Nacetyl-L-aspartic acid in rats. Food Chem Toxicol 2011;1:155-65.

Kera Y, Aoyama H, Watanabe N, Yamada R. Distribution of D-aspartate oxidase and free D-glutamate and D-aspartate in chicken and pigeon tissues. Comp Biochem Physio B Biochem Mol Biol 1996;115:121-6.

Kobayashi K, Pillai KS. Transformation of data and outliers. A Handbook of Applied Statistics in Pharmacology. CRC Press: Taylor \& Francis Group; 2013. p. 37-46.

Koutoku T, Takahashi H, Tomonaga S, Oikawa D, Saito S, Tachibana T, et al. Central administration of phosphatidylserine attenuates isolation stress-induced behavior in chicks. Neurochem Int 2005;47:183-9.

Koyuncuoğlu H, Berkman K. Effect of D- and/or L-aspartic acids on feeding, drinking, urine outflow and core temperature. Pharmacol Biochem Behav 1982;17:1265-9.

Koyuncuoğlu H, Berkman K, Wildmann J, Matthaei H. Antagonistic effect of L-aspartic acid on decrease in body weight, and food and fluid intake, and naloxone reversible rectal temperature depression caused by D-aspartic acid. Pol J Pharmacol Pharm 1982a;34 $333-7$

Koyuncuoğlu H, Wildmann J, Berkman K, Matthaei H. The effects of D- and/or L-aspartic acids on the total weight of body, the weights of certain organs, and their protein, triglyceride and glycogen content. Arzneimittelforschung 1982b;32:738-41.

Koyuncuoğlu H, Berkman K, Hatipoğlu I, Sabuncu H. Vasopressin release by D-aspartic acid, morphine and prolyl-leucyl-glycinamide (PLG) in DI Brattleboro rats. Pharmacol Biochem Behav 1984;20:519-25.

Leeson S. Nutritional considerations of poultry during heat stress. Worlds Poult Sci J 1986 42:69-81.

Lin H, Mertens K, Kemps B, Govaerts T, Deketelaere B, Debaerdemaeker J, et al. New approach of testing the effect of heat stress on egg quality: mechanical and material properties of eggshell and membrane. Br Poult Sci 2004;45:476-82.

Marley E, Stephenson JD. Effects of noradrenaline infused into the chick hypothalamus on thermoregulation below thermoneutrality. J Physiol 1975;245:289-303.

Meluzzi A, Primiceri G, Giordani R, Fabris G. Determination of blood constituents reference values in broilers. Poult Sci 1991;71:337-45.

Mendes AA, Watkins SE, England JA, Saleh EA, Waldroup AL, Waldroup PW. Influence of dietary lysine levels and arginine:lysine ratios on performance of broilers exposed to heat or cold stress during the period of three to six weeks of age. Poult Sci 1997;76: 472-81.

Monda M, Viggiano A, De Luca V. An aversive diet as thiamine-free food blocks foodinduced release of excitatory amino acids in the accumbens. Acta Physiol Scand 2003:3:197-203.

Neidle A, Dunlop DS. Developmental changes of free D-aspartic acid in the chicken embryo and in the neonatal rat. Life Sci 1990;46:1517-22.

Okuno A, Yamamoto M, Itoh S. Lowering of body temperature induced by vasopressin. Jpn J Physiol 1965;15:378-87.

Rose SP, Salah Uddin M. Effect of temperature on the response of broiler chickens to dietary lysine balance. Br Poult Sci 1997;38:S36-7.

Saito ES, Kaiya H, Takagi T, Yamasaki I, Denbow DM, Kangawa K, et al. Chicken ghrelin and growth hormone-releasing peptide-2 inhibit food intake of neonatal chicks. Eur J Pharmacol 2002;453:75-9.

SAS Institute. Version 9.1. Cary., NC, USA: SAS Institute Inc; 2002.

Sawyer WH, Munsick RA, Van Dyke HB. Evidence for the presence of arginine vasotocin (8-arginine oxytocin) and oxytocin in neurohypophyseal extracts from amphibians and reptiles. Gen Comp Endocrinol 1961;1:30-6.

Schieber A, Brückner H, Rupp-Classen M, Specht W, Nowitzki-Grimm S, Classen HG. Evaluation of D-amino acid levels in rat by gas chromatography-selected ion monitoring mass spectrometry: no evidence for subacute toxicity of orally fed D-proline and Daspartic acid. J Chromatogr B Biomed Sci Appl 1997;1:1-12.

Stallone JN, Braun EJ. Regulation of plasma arginine vasotocin in conscious waterdeprived domestic fowl. Am J Physiol 1986;250:R658-64.

Stegink LD. Absorption, utilization, and safety of aspartic acid. J Toxicol Environ Health 1976;1:215-42.

Sterling KG, Bell DD, Pesti GM, Aggrey SE. Relationships among strain, performance, and environmental, temperature in commercial laying hens. J Appl Poult Res 2003;12: $85-91$.

Tachibana T, Saito ES, Saito S, Tomonaga S, Denbow DM, Furuse M. Comparison of brain arginine-vasotocin and corticotrophin-releasing factor for physiological responses in chicks. Neurosci Lett 2004;360:165-9.

Tada Y, Yano N, Takahashi H, Yuzawa K, Ando H, Kubo Y, et al. Toxic effects of l-aspartic acid at high dose levels on kidneys and salivary glands in Fischer 344 rats detected in a 90-day feeding study. Food Chem Toxicol 2008;46:2789-95.

Takahashi $\mathrm{H}$, Jigo M, Ando K, Tachibana T, Denbow DM, Furuse M. Regulation of body temperature by thyrotropin-releasing hormone in neonatal chicks. Brain Res Dev Brain Res 2005; 157:58-64.

Teeter RG, Belay T. Broiler management during acute heat stress. Anim Feed Sci Technol 1996:58:127-42.

Yahav S. Domestic fowl-strategies to confront environmental conditions. Avian Poult Biol Rev 2000;11:81-95.

Yamane $\mathrm{H}$, Asechi M, Tsuneyoshi Y, Kurauchi I, Denbow DM, Furuse M. Intracerebroventricular injection of L-aspartic acid and L-asparagine induces sedative effects under an acute stressful condition in neonatal chicks. Anim Sci J 2009;80:286-90.

Yanni AE, Yatzidis HA, Kavantzas NG, Agapitos EV, Perrea DN, Karayannacos PE. Dietary Laspartate and L-glutamate inhibit fatty streak initiation in cholesterol-fed rabbit. Nutr Metab Cardiovasc Dis 2003;13:80-6.

Yanni AE, Perrea DN, Yatzidis HA. Effect of antiatherogenic L-aspartate and L-glutamate on serum lipoproteins cholesterol and apolipoproteins A-1 and B in rabbits fed with high cholesterol diet. Nutr Metab Cardiovasc Dis 2005:15:161-5.

Yanni AE, Agrogiannis G, Nomikos T, Fragopoulou E, Pantopoulou A, Antonopoulou S, et al. Oral supplementation with L-aspartate and L-glutamate inhibits atherogenesis and fatty liver disease in cholesterol-fed rabbit. Amino Acids 2010;5: 1323-31. 